\title{
Assessing the Shrinkage Cracking Potential of Concrete Using Ring Specimens with Different Boundary Conditions
}

\author{
Bruce Menu (D), Marc Jolin (D), and Benoit Bissonnette $(\mathbb{D}$ \\ Research Centre on Concrete Infrastructure (CRIB), Université Laval, Québec City, QC G1V 0A6, Canada \\ Correspondence should be addressed to Bruce Menu; bruce-gandhi.menu.1@ulaval.ca
}

Received 18 October 2019; Revised 28 January 2020; Accepted 3 February 2020; Published 7 May 2020

Academic Editor: Hongtao Zhu

Copyright ( $\odot 2020$ Bruce Menu et al. This is an open access article distributed under the Creative Commons Attribution License, which permits unrestricted use, distribution, and reproduction in any medium, provided the original work is properly cited.

\begin{abstract}
Early-age cracking due to restrained shrinkage affects the performance and service life of concrete structures. Recent studies are successfully making use of the free ring shrinkage test in conjunction with restrained shrinkage measurements for the evaluation of the cracking potential of cementitious materials. This study provides information to improve the interpretation of cracking in ring specimens and a theoretical approach for predicting the stress rate of thick ring specimens. Results show that the rate of strain development and the age-at-cracking vary with specimen drying direction and the exchange surface-to-volume ratio. The results further revealed that early-age shrinkage cracking depends more on the shrinkage rate than the magnitude of the shrinkage itself. Also, it was found that although the restrained ring specimens attained approximately similar strain levels, the cracking age varies significantly, suggesting that elastic stress-strength analysis alone may be inadequate for predicting early-age cracking due to the contribution of creep-relaxation phenomena.
\end{abstract}

\section{Introduction}

Shrinkage of cementitious materials is inevitable when the material is exposed to an environment with lower relative humidity (R.H.) and undergoes drying. If shrinkage is restrained, internal tensile stresses are progressively induced in the element and can eventually exceed the material's strength, leading to cracking. Drying shrinkage cracking is a major problem in concrete technology [1-5]. In particular, early cracking due to restrained shrinkage is a key issue in the long-term durability performance and service life of concrete elements. Indeed, many concrete structures worldwide require repair and rehabilitation, sometimes repeatedly, due to problems triggered by restrained shrinkage cracking. Many studies relating to shrinkage cracking have focused on the free shrinkage deformations. However, free drying shrinkage alone does not necessarily give a reliable indication of the risk of premature cracking. In fact, in addition to the magnitude of the shrinkage deformation, the risk for shrinkage cracking depends on a combination of phenomena and parameters, most importantly the concrete's tensile strength, elastic modulus, creep, and the effective degree of restraint.
In recent years, the ring test (e.g., AASHTO T334-08 [6] and ASTM C1581 [7]) has become the most widely used test method to evaluate and quantify the restrained shrinkage cracking sensitivity of cement-based materials. The test consists of casting a ring of concrete around an inner steel ring, which provides a uniform restriction to the concrete contraction when it is exposed to drying. The restriction to movement results in the development of compressive strain in the steel ring when the concrete ring shrinks. The steel ring is generally equipped with strain gauges for monitoring the strain variation as the concrete specimen shrinks against it. A sudden decrease in one or more of the strain gages indicates that the concrete specimen has cracked. Moreover, by continuously monitoring the strain development in the steel ring, it is possible to calculate a corresponding stress and, from mechanical equilibrium considerations, the average stress in the concrete ring [8-12]. Thus, the ring test is not intended to only measure the time to cracking but also to provide comparative restrained shrinkage data on mixtures.

The ring test method is well established for evaluating the shrinkage cracking sensitivity of ordinary cast concrete $[8,9,12,13]$, but its use to assess shrinkage cracking of shotcrete has hardly been studied. The reader must understand 
that shotcrete is distinctly different from cast concrete due to its unique mix designs, placement techniques, compaction dynamics, strength gain mechanisms, and internal structure [14]. The shotcrete process is complex in many aspects as the final in-place quality relies upon the interaction of a chain of phenomena (such as the nozzle manipulation, air flow, material flow, shooting consistency, and rebound) during spraying. Thus, our conventional understanding of the shrinkage cracking behavior of cast concrete under restrained conditions can be applied to shotcrete only with caution. For the proper evaluation of cracking potential of shotcrete, the specific material proportions and properties and, most importantly, theplacement technique need to be considered [15].

The orientation of the ring test mold, in particular, must be taken into consideration due to material rebound (i.e., particles ricocheting off the target during spraying). Rebound particles, if entrapped into the fresh shotcrete, can create defects that would negatively influence the ring test results [15]. The shotcrete techniques also make spraying a shotcrete ring specimen difficult because of the geometry and the limited available space in the ring mold. This makes the AASHTO ring test setup more preferable to the ASTM C1581 ring test setup because it offers more room to accommodate the shotcrete spray, thus enabling easier achievement of homogeneity inside the specimen [15]. For this reason, an earlier study was conducted at the Laval University Shotcrete Laboratory (Quebec City, Canada) to adapt the AASHTO ring test for sprayed concrete focused primarily on the interpretation of data. This paper presents a data analysis method on the basis of average stress and stress rate at cracking for shotcrete in accordance with the AASHTO T334-08 procedure [6].

A simple approach based on the mechanical equilibrium between the inner steel ring and the outer concrete ring was implemented for determining the average stress developed in the concrete. Many approaches $[8,10,12,16]$ have been proposed for estimating the maximum stress development in the thick concrete ring. A common simplifying assumption in these approaches is the applicability of the theory of elasticity to concrete, which is, in fact, a viscoelastic material. The approach proposed in this study is independent of the elastic or viscoelastic nature of the material.

Additionally, a data analysis method on the basis of the stress rate at the cracking ring has been developed for the thick AASHTO ring in this study. It should be noted that a similar solution has been recently proposed for the thin ASTM ring [13]. However, the proposed analysis is inadequate for thick concrete rings (as used in this study), which show different cracking behavior compared to thin concrete rings. For example, specimens made with thicker AASHTO ring would take longer to crack compared to the thinner ASTM ring. Moreover, as previously stated, the AASHTO ring is preferable for shotcrete because it offers more room to accommodate the shotcrete spray.

It should be emphasized that the size (thickness and height) and drying configuration (exposed surface(s)) of a ring test specimen significantly influence the drying process and, thereby, the resulting shrinkage and cracking behavior. Nevertheless, only a few studies (such as ref. [17]) have examined the influence of boundary conditions on cracking of mortars using "nonstandardized" thick ring specimens. In the present study, the AASHTO T 334-08 [6] ring procedure was used to appraise the influence of the boundary conditions (i.e., drying direction) and the exchange surface to-volume-ratio $\left(S_{e} / V\right)$ on shrinkage and the associated cracking of thick AASHTO ring specimens. The findings are expected to provide guidance towards the implementation of a suitable drying method for shotcrete ring tests to ensure that cracking would occur in a reasonable amount of time.

It is expected that the experimental investigations presented here will help to better understand the cracking behavior of shotcrete. The ring test procedure recently developed for sprayed concrete [15] is increasingly being adopted or used extensively by the shotcrete industry to assess the cracking behavior of shotcrete mix designs. The data analysis methods presented here will help to better interpret the data thus obtained from the ring test procedure recently developed for sprayed concrete [15]. Overall, the present study is part of the ongoing research on the durability of concrete and shotcrete mixtures and is aimed at better characterizing the drying shrinkage cracking potential of shotcrete, through improved interpretation of the ring test results. The AASHTO T 334-08 ring procedure was modified to quantify both the restrained and free shrinkage behavior of shotcrete mixtures.

1.1. Research Synopsis. The restrained shrinkage ring test is the most widespread test for characterizing the shrinkage cracking potential of cementitious materials. The present paper indicates how it can be used to quantify stress development in concrete undergoing restrained shrinkage. The paper provides useful information on the influence of drying direction (boundary conditions) upon stress development and age at cracking in the restrained ring specimen. An analytical equation based on mechanical equilibrium is presented for estimating the average stress developing in the concrete ring. Additionally, the influence of the water-to-cement ratio $(\mathrm{w} / \mathrm{cm})$ and exchange surface-to-volume ratio is discussed. This study is of interest to engineers and material specifiers in view of better assessing and/or predicting the drying shrinkage sensitivity of concrete.

\section{Experimental Program}

To obtain a better understanding of the restrained shrinkage phenomenon in concrete and the influence of boundary conditions on shrinkage and stress development, free and restrained shrinkage tests were conducted. Series of test specimens were cast using the same prepackaged repair concrete mixture with nominal maximum aggregate size of $10 \mathrm{~mm}$, prepared with different water-to-cement $(\mathrm{w} / \mathrm{cm})$ ratios $(0.42,0.45$, and 0.60$)$ intended to cover fairly well the range from moderate to high water content mixtures. Except for the $0.60 \mathrm{w} / \mathrm{cm}$ mixture, a naphthalene-based superplasticizer was used to reach the desired workability, with a slump in the range of 100 to $140 \mathrm{~mm}$. The effective concrete mixture proportions used are provided in Table 1 . Note that 
TABLE 1: Concrete mixtures investigated.

\begin{tabular}{lcccc}
\hline $\mathrm{w} / \mathrm{cm}$ & OPC cement $\left(\mathrm{kg} / \mathrm{m}^{3}\right)$ & $2.5-10 \mathrm{~mm}$ crushed limestone $\left(\mathrm{kg} / \mathrm{m}^{3}\right)$ & $0.08-5 \mathrm{~mm}$ natural sand $\left(\mathrm{kg} / \mathrm{m}^{3}\right)$ & $\mathrm{Water}\left(\mathrm{kg} / \mathrm{m}^{3}\right)$ \\
\hline 0.42 & 451 & 746 & 1068 & 186 \\
0.45 & 445 & 736 & 1054 & 197 \\
0.60 & 417 & 689 & 988 & 247 \\
\hline
\end{tabular}

for the $0.42 \mathrm{w} / \mathrm{cm}$ mixture only restrained ring tests were performed to validate the proposed model and extend the interpretation of the restrained ring tests. The implemented test procedures are described in the following sections.

\subsection{Mechanical Characterization. The compressive} strength, splitting tensile strength, and modulus of elasticity were determined in accordance with ASTM C39, C496, and C469 test methods, respectively. Twenty-one $100 \times 200 \mathrm{~mm}$ cylinders were prepared for each of the three investigated concrete mixtures to carry out mechanical characterization tests. Sets of four cylinders were tested in compression at 3,7 , and 28 days to determine the modulus of elasticity, while sets of three cylinders were used to determine splitting tensile strength at 3,7 , and 28 days.

2.2. Restrained Shrinkage. The research work reported herein is part of a project intended to better understand and prevent cracking of shotcrete. Although a ring test procedure was developed especially for sprayed concrete in recent years [15], this paper focuses primarily on the interpretation of data, by assessing the early age cracking potential of wet-mix shotcrete mixtures cast conventionally in accordance with the AASHTO T334-08 procedure [6] (formerly AASHTO PP 34-99 [18]). As illustrated schematically in Figure 1, the inner diameter of the concrete ring is $305 \mathrm{~mm}$, its outer diameter is $457 \mathrm{~mm}$ (thickness of $76 \mathrm{~mm}$ ), and its height is $152 \mathrm{~mm}$. The restraining inner steel ring has the same height as that of the concrete, but the inner diameter and outer diameters of $280 \mathrm{~mm}$ and $305 \mathrm{~mm}$, respectively (thickness of $12.7 \mathrm{~mm}$ ). The degree of restraint with this particular geometry is of the order of 53 to $60 \%$, depending on the actual modulus of elasticity and creep of concrete (based on an analytical formula proposed by Moon et al. [9]). In comparison, the degree of restraint for the ASTM ring setup is higher (about 70 to $75 \%$ ) because of its smaller concrete wall thickness.

During the experiment, compressive strain develops in the inner steel ring as the outer concrete ring dries and shrinks against it. Four resistive strain gages installed on the interior face of the steel ring at mid-height, equidistant from each other, allows real-time monitoring of the deformation and, ultimately, detection of the cracking occurrence. For each mixture, experiments were conducted for two different moist curing periods, 3 and 7 days respectively. In each case, two separate test batches were prepared to provide a stronger basis for the conclusions to be drawn. At least four concrete ring specimens were cast per mixture in each of the replicate batches. On each occasion, the rings were divided into two, representing the two drying configurations investigated. After casting, the specimens were covered with wet burlap and plastic sheets and left in their mold for the first 24 hours. The exterior wall of the mold was removed after 24 hours, and the specimens were further moist cured for either 2 or 6 more days. The burlaps were wetted every day during the curing periods to ensure proper curing.

After curing, the specimens were sealed with adhesive aluminum tape in such a way that they could dry either along their radial direction, also referred to as "circumferential drying," or along their axial direction, also referred to as "top and bottom drying" from the side faces. The two investigated drying configurations are shown in Figure 2. The specimens were exposed to drying at $21 \pm 2^{\circ} \mathrm{C}$ and $50 \pm 4 \%$ R.H. until cracking occurred in all specimens of the set. In this study, strain monitoring began immediately after placement. Thus, all deformations occurring during the moist curing periods were recorded. The strain data were recorded at 5 minute intervals. The time at cracking can be detected quite precisely by a sudden sharp change in the strain gage readings (usually greater than 30 microstrains).

2.3. Free Shrinkage. The AASHTO T $334-08$ method comes without provisions or means for comparing restrained and free shrinkage. For free drying shrinkage measurements, ring specimens identical in size to the AASTHO rings were cast, but with the inner steel ring replaced with a core made of a very low stiffness material with respect to that of concrete. The objective was to measure free shrinkage on specimens having the same geometry, size, and exposed surface-tovolume ratio such that they undergo the same drying conditions as the restrained rings. In the free ring test, the concrete specimen is not restrained and hence can shrink "freely." DEMEC gages are installed on top of the free ring specimens for length change measurements (4 chord lengths distributed over the circumference). For each set of AASHTO ring specimens ( 0.45 and $0.60 \mathrm{w} / \mathrm{cm}$ mixtures), the same number of free companion rings was cast in accordance with the same protocol, except for the inner steel ring, replaced with an expanded polystyrene (EPS) core (very low stiffness). The detailed method is described elsewhere [19]. The free ring specimens underwent the curing and drying regimens described in Section 2.2. Free shrinkage measurements were taken regularly throughout the AASHTO ring monitoring period, from the time of demolding ( \pm 24 hours).

\section{Analysis of Restrained Ring Shrinkage Test}

In the restrained ring test, the strain measured in the steel ring can be used to estimate the tensile stress that develops in the concrete ring [8-10]. In general, the stress distribution is analyzed based on the assumption of a frictionless relative 


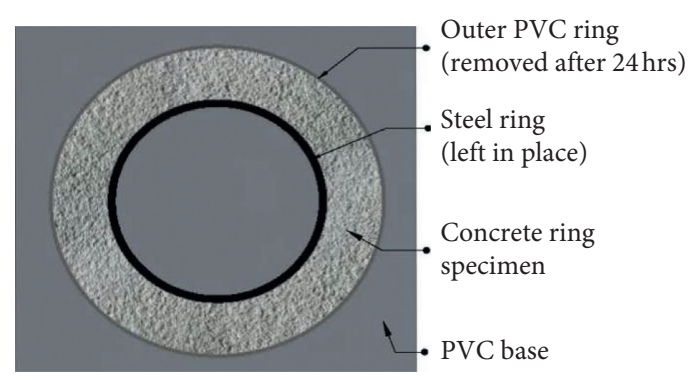

(a)

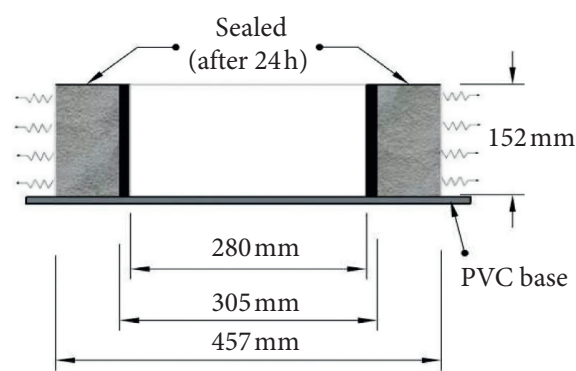

(b)

FIgure 1: Ring test setup used in the AASHTO T334-08 ring test. (a) Top view. (b) Front view.

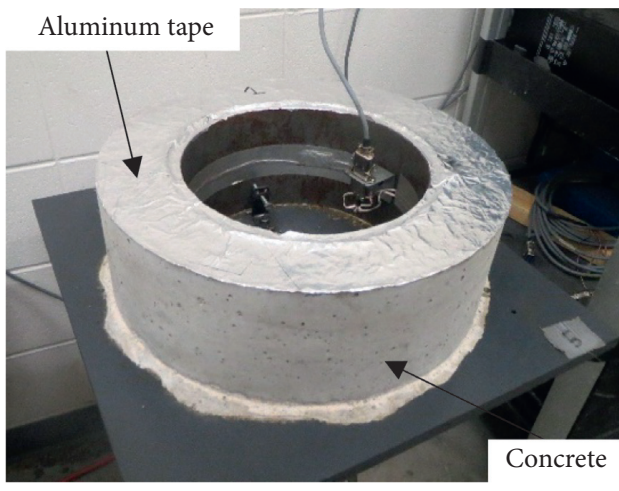

(a)

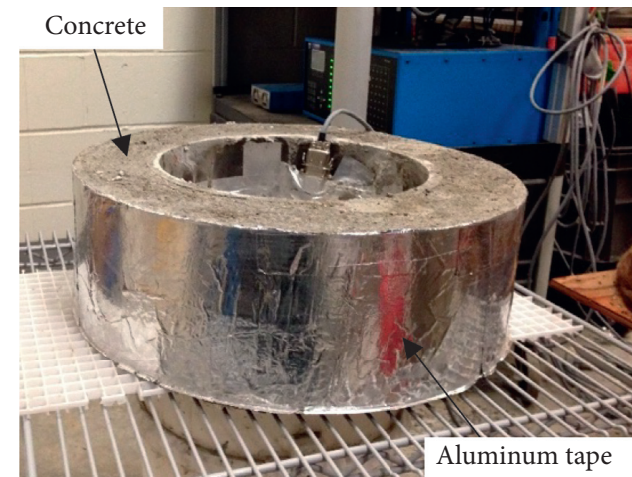

(b)

FIGURE 2: AASHTO T334-08 ring test specimens sealed (a) on top and bottom faces (i.e., radial drying) and (b) on the outer circumferential face (i.e., axial drying).

movement between the two rings, with the steel ring being subjected to an external pressure $P_{s}$ and the concrete ring being subjected to a reciprocal internal pressure $P_{c}$, as shown in Figure 3. See et al. [13] proposed expressions that are applicable to thin concrete rings. The approach is based on the classical approach of thin-walled cylinders and is derived from an equilibrium calculation of the same kind as that considered in this study.

For thick-walled concrete rings, Weiss et al. [8, 12, 16] proposed a general expression for determining the maximum residual tensile stress that develops at the interface and Mojabi-Sangnier [10] proposed a similar solution for determining the average tensile stress. A common simplifying assumption in both approaches is the applicability of the theory of elasticity to concrete, which is, in fact, a viscoelastic material. Moreover, it was found by Moon and Weiss [11] that these equations were only suitable for uniform drying along the radial direction.

In this paper, a simplified approach based on the mechanical equilibrium between the steel and concrete rings for determining the average stress development in thick concrete ring specimens is proposed. In this approach, the theory of elasticity is applied to the steel ring. Since steel behaves elastically in the ring test, the average forces in the steel ring due to the pressure at the interface can be determined based on the elastic theory. By equilibrium of forces, the resulting force in the concrete ring must equal that calculated in the steel ring. The solution is valid independent of the nature of the material (elastic or viscoelastic).

3.1. Determination of Average Tensile Stress. Mechanical equilibrium requires that irrespective of the drying conditions imposed on the concrete ring specimen, as contact pressure builds up at the interface between the two rings, the resulting internal forces in the inner and outer rings balance out, as shown in Figure 4. The overall equilibrium can simply be described as follows:

$$
F_{s}+F_{c}=0 \Longrightarrow F_{s}=-F_{c} \text {, }
$$

where $F_{s}$ and $F_{c}$ are the internal resulting forces induced in the steel and concrete rings, respectively. Irrespective of the fact that the contact pressure may vary across the width of the rings, the relationship between the average stresses in the steel and concrete ring can thus be described as follows:

$$
F_{s}=-F_{c} \Longrightarrow \sigma_{s_{\text {avg }}}(t) A_{s}=-\sigma_{c_{\text {avg }}}(t) A_{c}
$$

where $\sigma_{s_{\text {avg }}}$ and $\sigma_{c_{\text {avg }}}$ are the average stresses at a time, $t$, in the steel ring and concrete ring, respectively, while $A_{s}$ and $A_{c}$ are the corresponding cross-sectional areas. 


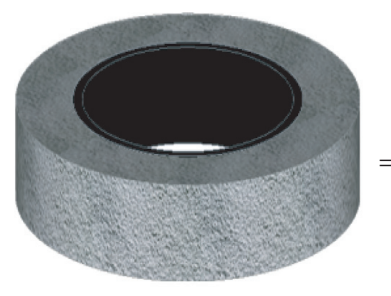

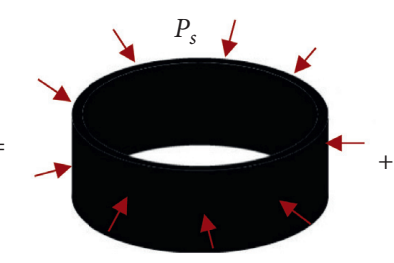

Pressure on steel ring

(a)

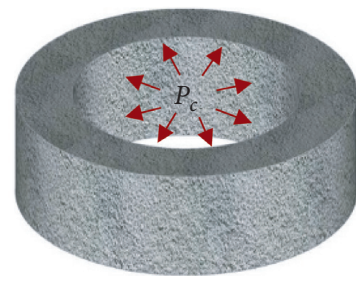

Pressure on concrete ring

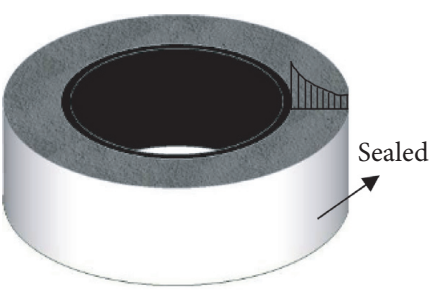

Drying from axial direction (b)

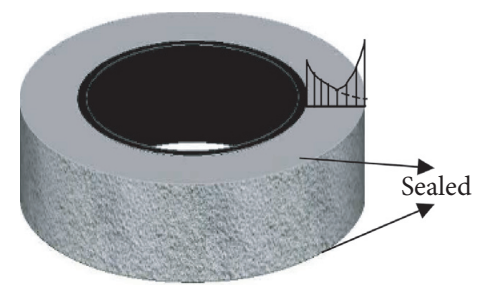

Drying from radial direction

(c)

FIGURE 3: Schematical illustration of (a) contact pressure acting in the steel ring and the concrete ring, (b) stress profile when drying from axial direction, and (c) stress profile when drying from radial direction.

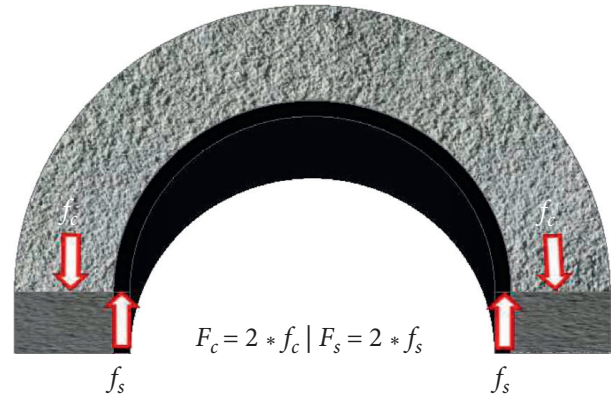

FIGURE 4: Schematical illustration of the internal forces developing in the rings.

From the classical thick-walled cylinder solution, the elastic stress distribution in the steel ring (Figure 3) at a radius $r$ is obtained as follows:

$$
\sigma_{s}(r)=-\frac{1}{r^{2}}\left(\frac{\left[R_{\mathrm{os}}^{2}\left(r^{2}+R_{\mathrm{is}}^{2}\right)\right]}{\left(R_{\mathrm{os}}^{2}-R_{\mathrm{is}}^{2}\right)}\right) \cdot P_{s},
$$

where $P_{s}$ is the external pressure exerted on the steel ring, $r$ is the radial distance, $R_{\mathrm{is}}$ is the inner steel ring radius, and $R_{\mathrm{os}}$ is the outer steel ring radius. The strain in the steel ring can then be obtained as follows:

$$
\varepsilon_{s}(r)=\frac{\delta_{s}(r)}{r}
$$

where $\delta_{s}$ is the displacement of the outer surface of the steel ring which can be calculated as follows:

$$
\delta_{s}(r)=-\frac{1}{E_{s}} \cdot\left[\frac{R_{\mathrm{os}}^{2}}{r\left(R_{\mathrm{os}}^{2}-R_{\mathrm{is}}^{2}\right)}\right] \cdot\left[\left(r^{2}+R_{\mathrm{is}}^{2}\right)+\nu_{s}\left(r^{2}-R_{i s}^{2}\right)\right] \cdot P_{s} \text {, }
$$

where $E_{s}$ is the modulus of elasticity of the steel [200 GPa $\left.\left(29 \times 10^{6} \mathrm{psi}\right)\right], \quad \nu_{s}$ is Poisson's ratio of the steel ring $(\approx 0.30)$. Combining equations (4) and (5), the strain in the steel ring can be determined with the following expression:

$$
\varepsilon_{s}(r)=-\frac{1}{E_{s}} \cdot\left[\frac{R_{\mathrm{os}}^{2}}{r^{2}\left(R_{\mathrm{os}}^{2}-R_{\mathrm{is}}^{2}\right)}\right] \cdot\left[\left(r^{2}+R_{\mathrm{is}}^{2}\right)+\nu_{s}\left(r^{2}-R_{\mathrm{is}}^{2}\right)\right] \cdot P_{s} .
$$

The strain measured on the inner face of the steel ring at any time $t$ can then be obtained as follows:

$$
\left.\varepsilon_{s}(t)\right|_{r=R_{\mathrm{is}}}=\varepsilon_{s}(t)=-\frac{2}{E_{s}}\left[\frac{R_{\mathrm{os}}^{2}}{\left(R_{\mathrm{os}}^{2}-R_{\mathrm{is}}^{2}\right)}\right] \cdot P_{s} .
$$

Combining equations (3) and (7), to remove $P_{s}$, the elastic stress distribution in the steel ring can be obtained from the following expression:

$$
\sigma_{s}(r)=\frac{1}{2} \cdot E_{s} \cdot \varepsilon_{s}(t) \cdot\left[\frac{\left(r^{2}+R_{\mathrm{is}}^{2}\right)}{r^{2}}\right] .
$$

The average steel ring elastic stress can then be determined by integrating $\sigma_{s}(r)$ over the thickness of the concrete section:

$$
\begin{aligned}
\sigma_{s_{\mathrm{avg}}}(r) & =\int_{r=R_{\mathrm{is}}}^{r=R_{\mathrm{os}}} \sigma_{s}(r) \mathrm{d} r \int_{r=R_{\mathrm{is}}}^{r=R_{\mathrm{os}}} \mathrm{d} r \\
& =\frac{1}{2} \cdot E_{s} \cdot \varepsilon_{s}(t) \cdot\left(\frac{\left[r-\left(R_{\mathrm{is}}^{2} / r\right)\right]_{R_{\mathrm{is}}}^{R_{\mathrm{is}}}}{[r]_{R_{\mathrm{is}}}^{R_{\mathrm{s}}}}\right) .
\end{aligned}
$$

The average stress in the steel at any given time $t$ can be determined with the following expression: 


$$
\sigma_{s_{\mathrm{avg}}}(t)=\frac{1}{2} \cdot E_{s} \cdot \varepsilon_{s}(t) \cdot\left[\frac{\left(R_{\mathrm{os}}+R_{\mathrm{is}}\right)}{R_{\mathrm{os}}}\right] .
$$

Considering equations (2) and (10), the average tensile stress in the concrete ring is obtained as follows:

$$
\sigma_{c_{\text {avg }}}(t)=-\frac{1}{2} \cdot \frac{A_{s}}{A_{c}} \cdot E_{s} \cdot \varepsilon_{s}(t) \cdot\left[\frac{\left(R_{\mathrm{os}}+R_{\mathrm{is}}\right)}{R_{\mathrm{os}}}\right] .
$$

The geometrical and material properties are constant for a given ring setup; hence, the tensile stress induced in the concrete ring can simply be written as follows:

$$
\sigma_{c_{\mathrm{avg}}}(t)=-G \cdot \varepsilon_{s}(t)
$$

where $G$ is a constant for the ring setup and is obtained as follows:

$$
G=\left[\frac{\left(R_{\mathrm{os}}+R_{\mathrm{is}}\right)}{2 R_{\mathrm{os}}}\right] \cdot\left(\frac{A_{s} E_{s}}{A_{c}}\right) .
$$

For the ring setup used in this study, $G=31.55 \mathrm{GPa}$ $\left(4.58 \times 10^{6} \mathrm{psi}\right)$. The $G$ here is synonymous with the term $G$ derived by See et al. [13] for stress rate analysis in a thin ring specimen.

3.2. Determination of Stress at Cracking. Although the cracking age and the average tensile stress analysis are an interesting benchmark, analyzing ring test results can be further extended by developing a practical method for evaluating the test results based on the stress rate. The stress rate proposed in this study for thick rings is based on a similar analysis carried out by See et al. [13] for thin concrete rings. It should be noted that the average tensile stress analysis does not directly use the moisture gradient for calculating the stress developments. Although attempts have been made in the past to consider the stress induced by the moisture gradient [11], a direct application of the suggested solution in [11] is not straightforward since it is difficult to validate and calibrate the parameters needed for the procedure. The stress rate method is thus a more practical approach to quantifying the cracking potential of mixtures. Indeed, a recent study has shown that the average residual stress at cracking considering moisture gradient is inversely proportional to the square root of time-to-cracking [20].

For small changes in $t$, the stress rate after initiation of drying in the ring can be expressed as follows:

$$
S(t)=\frac{\mathrm{d} \sigma_{c_{\text {avg }}}(t)}{\mathrm{d} t}=G\left|\left(\frac{\mathrm{d} \varepsilon_{s}}{\mathrm{~d} t}\right)\right|,
$$

where $\mathrm{d} \varepsilon_{s} / \mathrm{d} t$ is the net steel strain rate at time $t$. Attiogbe et al. [20] found that the steel strain $\left(\varepsilon_{s}\right)$ is proportional to the square root of drying time up to the time to cracking. It can therefore be fitted using a linear regression as follows:

$$
\varepsilon_{s}(t)=\alpha \sqrt{t}+c
$$

where $\alpha$ is the slope of the linear function, or the strain rate $\left(\mu \mathrm{m} /\right.$ day $\left.^{1 / 2}\right)$, and $c$ is a regression constant. Thus, from equations (14) and (15), the stress rate during drying is given by

$$
S(t)=\frac{G|\alpha|}{2 \sqrt{t}}
$$

The stress rate at cracking for each test mixture is determined from equation (16) by substituting the time to cracking, $t_{\mathrm{cr}}$, in place of time, $t$. This stress rate will be used to complement the usual "time to cracking" used in analyzing the ring test data. It should be noted that equation (16) is a general solution applicable to both thin and thick ring specimens (where $G=72.2 \mathrm{GPa}\left(10.47 \times 10^{6} \mathrm{psi}\right)$ for thin ring specimens $[13,20]$, while $G=31.55 \mathrm{GPa}\left(4.58 \times 10^{6} \mathrm{psi}\right)$ for ring specimens).

\section{Test Results and Discussion}

4.1. Mechanical Properties. The compressive strength $\left(f_{c}\right)$, (splitting) tensile strength $\left(f_{t}\right)$, and modulus of elasticity $\left(E_{c}\right)$ tests performed at 3,7 , and 28 days for the w/cm of 0.45 and 0.60 mixtures are presented in Table 2. Each mechanical property test data reported is the average of the three test specimens. The results show that strength is a function of the $\mathrm{w} / \mathrm{cm}$ ratio, as expected. An increase in compressive strength with age was also noted. The tensile strength and modulus of elasticity values unsurprisingly follow the same trend as the compressive strength.

4.2. Free Shrinkage of Concrete. The free drying shrinkage strains recorded for the $0.45 \mathrm{w} / \mathrm{cm}$ and $0.60 \mathrm{w} / \mathrm{cm}$ concrete mixtures are presented in Figure 5. On each graph, the shrinkage as a function of time is shown for the two drying conditions (radial and axial drying) with the corresponding curing regimes investigated. Each data point is an average of values recorded for at least two companion ring specimens. As previously stated, only restrained shrinkage tests were performed with the $0.42 \mathrm{w} / \mathrm{cm}$ mixture to validate equation (12) developed in this study and to extend the interpretation of the restrained shrinkage ring test experiment. It is interesting to observe from Figure 5 that the moist curing duration of concrete before exposure to drying influences the rate of drying shrinkage. It can be seen that prolonged moist curing results in an early reduction in drying shrinkage, which is found to somehow stabilize after some time.

It is further observed that prolonged moist curing had a slightly larger influence in concrete with a lower $\mathrm{w} / \mathrm{cm}$ (0.45). The test results also indicate that drying shrinkage is slightly higher for specimens dried from the radial direction than for specimens dried from the axial direction. This is attributed to the slightly higher $S_{e} / V$ when dried from the radial direction $\left(0.0158 \mathrm{~mm}^{-1} v s .0 .0132 \mathrm{~mm}^{-1}\right)$. Overall, shrinkage occurs at a rapid rate in the days following the initiation of drying and, beyond a period of the order of 28 days, the rate of shrinkage decreases quite significantly.

The free drying shrinkage rate factor of the $0.45 \mathrm{w} / \mathrm{cm}$ and $0.60 \mathrm{w} / \mathrm{cm}$ concrete mixtures were evaluated using equation (15), where the steel strain $\left(\varepsilon_{s}\right)$ has been replaced with $\varepsilon_{\text {sh }}$ (free shrinkage strain). The strain rate values 
TABle 2: Compressive strength, tensile strength, and modulus of elasticity data.

\begin{tabular}{|c|c|c|c|c|c|c|}
\hline \multirow{2}{*}{ Time after casting (days) } & \multicolumn{3}{|c|}{$0.45 \mathrm{w} / \mathrm{cm}$} & \multicolumn{3}{|c|}{$0.60 \mathrm{w} / \mathrm{cm}$} \\
\hline & $f_{c}(\mathrm{MPa})$ & $f_{t}(\mathrm{MPa})$ & $E_{c}(\mathrm{GPa})$ & $f_{c}(\mathrm{MPa})$ & $f_{t}(\mathrm{MPa})$ & $E_{c}(\mathrm{GPa})$ \\
\hline 3 & 26.9 & 2.5 & 25.8 & 25.5 & 2.4 & 25.4 \\
\hline 7 & 30.6 & 2.8 & 26.8 & 27.8 & 2.5 & 26.3 \\
\hline 28 & 37.5 & 3.4 & 30.0 & 33.4 & 2.7 & 28.8 \\
\hline
\end{tabular}

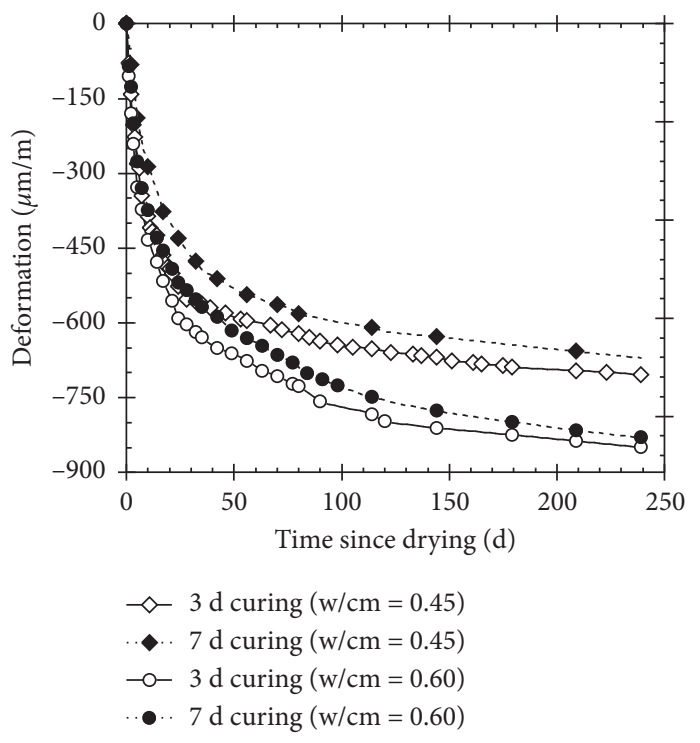

(a)

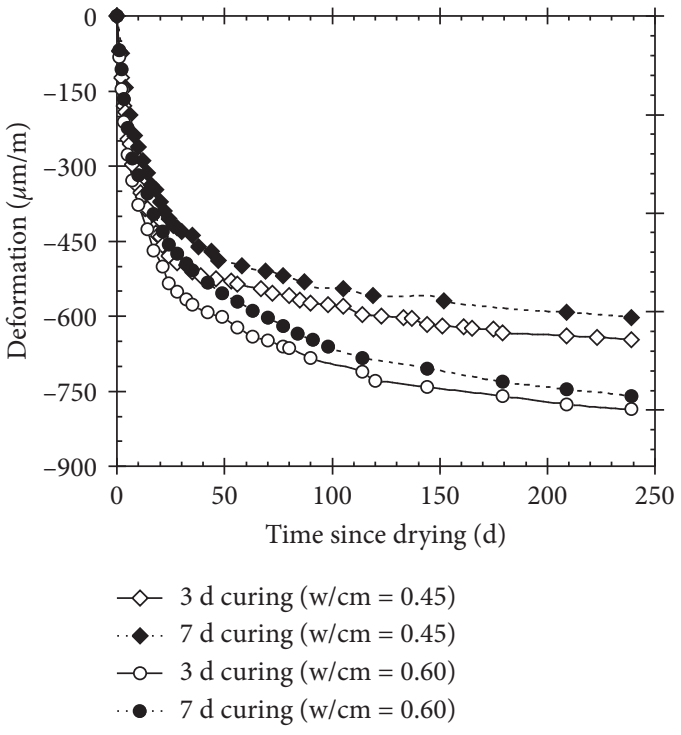

(b)

FIGURE 5: Free shrinkage test results from companion ring specimens subjected to (a) radial drying and (b) axial drying.

determined for the 0.45 and $0.60 \mathrm{w} / \mathrm{cm}$ mixtures are presented in Figure 6. Overall, the test results show that the strain rate increases with the $S_{e} / V$ ratio. Indeed, this has to be expected since drying is strongly influenced by the surface area where the exchanges take place $[1,17]$. The impact of a longer curing period is found to be more pronounced as the $\mathrm{w} / \mathrm{cm}$ decreases. Irrespective of the specimen drying configuration, extending the moist curing period from 3 to 7 days did not affect the strain rate of the $0.60 \mathrm{w} / \mathrm{cm}$ mixture. On the contrary, for the $0.45 \mathrm{w} / \mathrm{cm}$ mixture, extending the moist curing period resulted in a significantly lower strain rate factor.

4.3. Cracking of Restrained Concrete. Typical results of the evolution of the average tensile stress developing in the restrained concrete specimen, as estimated based on the data from the strain gages located on the inner face of the steel ring and equation (12), are shown in Figure 7. The graph shows the shrinkage-induced stress curves of three-ring test specimens made from the same batch of the $0.42 \mathrm{w} / \mathrm{cm}$ concrete mixture and drying from the radial direction. The age at cracking refers to the age at which cracking initiates in the ring specimen. Overall, the results in Figure 7 show that immediately upon exposure to drying, concrete starts shrinking, inducing in the steel ring a compressive stress that increases at a decreasing rate until failure, at which time a sudden change is recorded from the strain gages and a visible crack has developed in the restrained ring specimens. Thus, stress development in the ring specimen ultimately results in cracking of the restrained specimen. It can be observed from the experimental results in Figure 7 that specimen cast from the same batch (and stored in the same environmental conditions) do not necessarily crack at the same time. This phenomenon is quite usual in restrained ring tests [5]. This can be partly attributed to the intrinsic concrete variability which is influenced by a number of factors, notably the heterogeneous character of concrete and the placement process.

Indeed, the properties of concrete (particularly strength, elastic modulus, and tensile creep) are inherently characterized by some spatial variability, but the properties are not random as such. In general, the stress induced in the ring increases progressively, getting closer to the tensile strength. Failure will, therefore, occur at the location of a defect or weakness, thereby explaining the potentially significant differences in time to cracking between individual specimens. Nevertheless, it can be seen that the actual maximum recorded stress values are close at the age of cracking in the ring specimen.

4.4. Influence of Boundary Conditions on the Age of Cracking. There has been some debate over the years regarding the drying conditions in ring tests designed for evaluating the restrained shrinkage behavior of cementitious materials. 


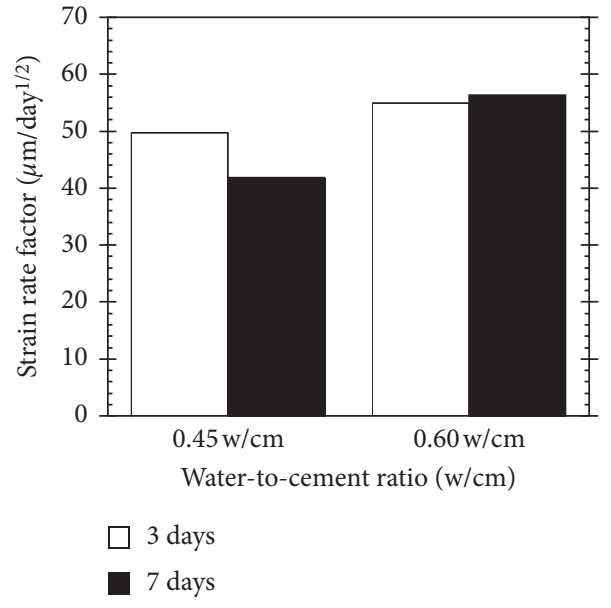

(a)

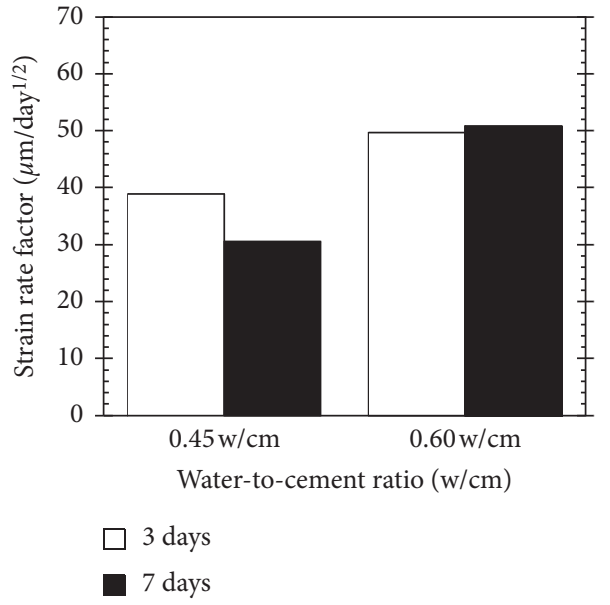

(b)

FIGURE 6: Free shrinkage test results from companion ring specimens, strain rate factors: (a) radial drying and (b) axial drying.

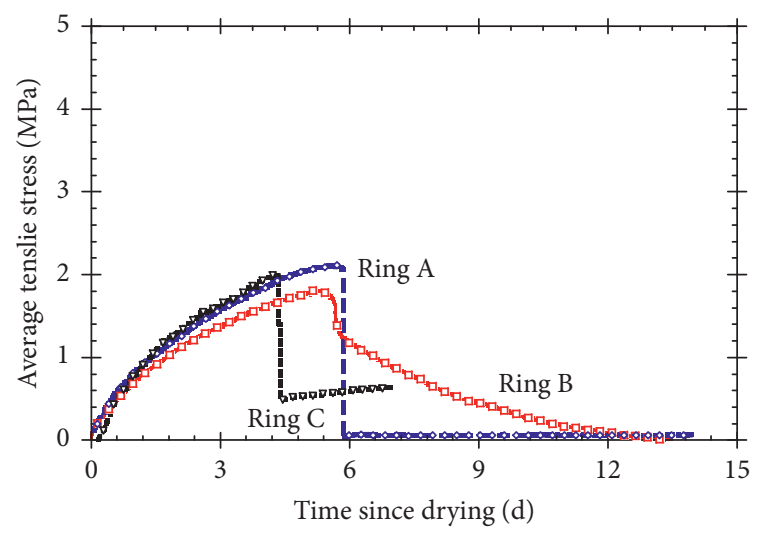

FIGURE 7: AASHTO T334 restrained shrinkage test results $-0.42 \mathrm{w} /$ $\mathrm{cm}$ mixture.

In the program reported herein, the influence of the drying direction was studied. The ring specimens were sealed in such a way to undergo one-directional drying, either axially or radially. Each of these conditions implies a certain $S_{e} / V$ ratio, which necessarily influences the drying process and, in turn, the shrinkage and self-stress rates. The results obtained in both drying conditions are summarized in Figure 8 for the $0.45 \mathrm{w} / \mathrm{cm}$ and $0.60 \mathrm{w} / \mathrm{cm}$ concrete mixtures. On each graph, the average stress as a function of drying time is shown. Each data point is the average of values recorded on at least two test specimens. Overall, a sudden drop in the steel ring compressive strain was recorded in all tests, except for the $0.45 \mathrm{w} / \mathrm{cm}$ specimens drying from the axial direction and cured for 7 days where a gradual loss of strain was encountered instead.

As expected, the results show that the drying direction has a significant influence on the age of cracking in the ring specimen. It was observed that the rate of drying is more rapid in specimens where the moisture exchange occurs in the radial direction in comparison to those exposed axially, for both the 0.45 and $0.60 \mathrm{w} / \mathrm{cm}$ concrete mixtures. Furthermore, a larger variation in time to cracking was observed when ring specimens are drying along the axial direction. Also, the test specimens drying from the radial direction cracked at an earlier age ( 8 to 14 days) compared with the specimens dried from the axial direction surfaces (39 to 95 days). A comparison of the age at which crack is detected by a sudden drop in the strain gage is shown in Figure 9 for the two boundary conditions studied.

The more severe consequences observed in specimens dried from the radial direction can be attributed, at least in part, to the coupled effects of a higher $S_{e} / V$ and more unfavorable drying gradients. It is well known that shrinkage is highly sensitive to the exchange surface-to-volume ratio $[1,17,19,21]$. Therefore, the slightly higher $S_{e} / V$ of specimens drying along the radial direction implies that they will obviously shrink at a more rapid rate and therefore are likely to crack at an earlier age when concrete has a lower tensile strength. In specimens drying along the axial direction, the rate of moisture loss is slower, and it takes a longer time to reach a comparable magnitude of shrinkage. This allows for further strength gain and relaxation due to creep, overall resulting in an extended time to cracking.

The effect of $S_{e} / V$ upon drying reflects the fact that drying does not occur uniformly inside the material, obeying to highly nonlinear transport processes (diffusion driven). The nonuniform drying results in moisture gradients and, thereby, in differential shrinkage strains over the cross-section of the concrete specimen. In turn, because of the nonlinearity of the strain profile, internal stresses are induced (selfrestraint). In particular, areas where drying and shrinkage occur first, i.e., next to the exchange surfaces, can thus be subjected to important tensile stresses, as a significant portion of the free contraction is restrained by the inner part of the element, which has not undergone significant drying yet. Hence, nonlinear drying shrinkage causes per se the development of an internal restraint (or self-restraint), and the resulting stresses add up to those caused by external restraints.

The two drying conditions investigated in the present study, referred to as radial and axial, thus result in transient 


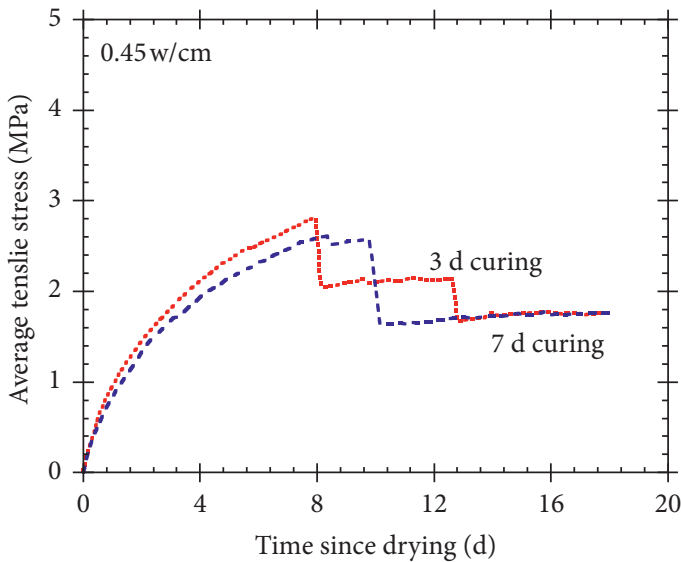

(a)

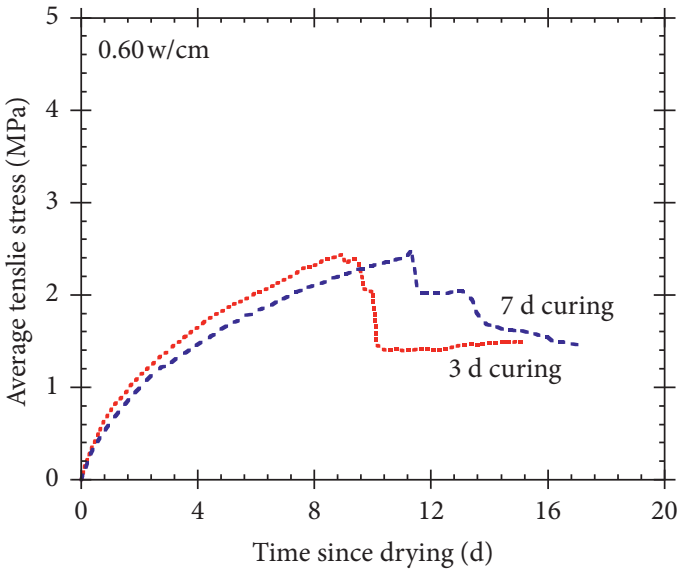

(c)

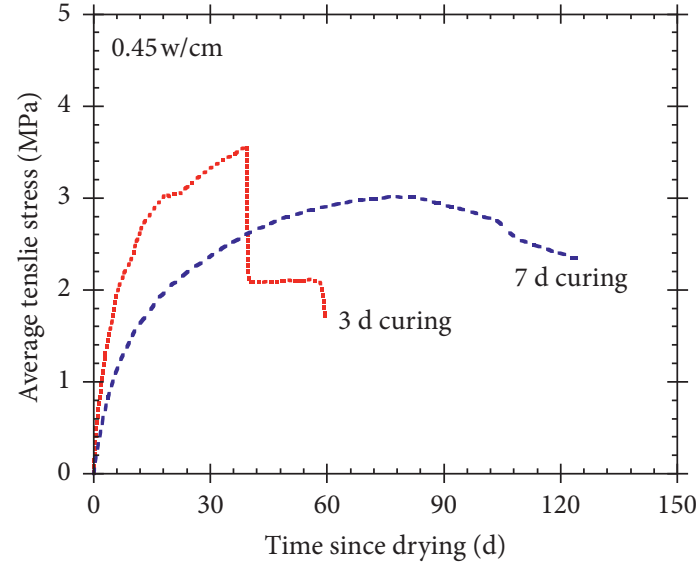

(b)

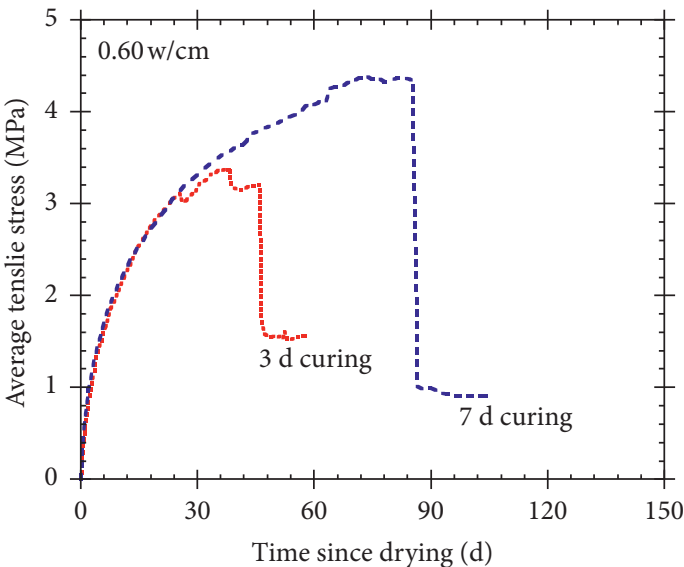

(d)

FIGURE 8: AASHTO T334 ring test results, influence of drying conditions: (a) $0.45 \mathrm{w} / \mathrm{cm}$ mixture, radial drying, (b) $0.45 \mathrm{w} / \mathrm{cm}$ mixture, axial drying, (c) $0.60 \mathrm{w} / \mathrm{cm}$ mixture, radial drying, and (d) $0.60 \mathrm{w} / \mathrm{cm}$ mixture, axial drying.

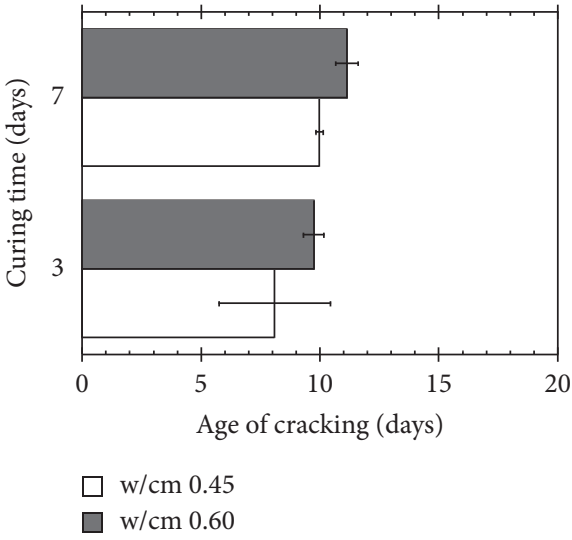

(a)

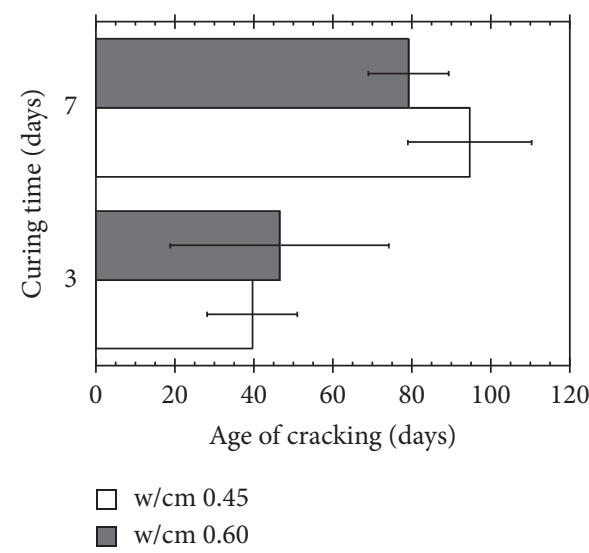

(b)

FIgURE 9: Age at (visible) cracking of restrained ring specimens. (a) Radial drying. (b) Axial drying.

moisture distributions, shrinkage gradients, and stress profiles that are quite different. In the case of axial drying, the transient moisture profile is uniform along the radial direction and nonuniform along the axial direction. For radial drying, it is exactly the opposite. As a consequence, the self-restraining effect is more pronounced in the radial drying layout. Considering the steel ring restrained is constant for the ring setup, it can be argued that, in the ring specimens drying from the radial direction, shrinkage cracking is mainly due to self-restraint. 
4.5. Effect of Strain Rate and Stress Rate on the Age of Cracking. Test results in Figures 8 and 9 show that cracking occurs earlier when drying from the radial direction, regardless of the $\mathrm{w} / \mathrm{cm}$ ratio. This behavior is primarily due to the higher stress rate which is directly dependent on the shrinkage rate. In fact, by comparing in Figures 8 and 10, it can be seen that higher strain rates actually lead to a shorter time to cracking in both tested mixtures. It can be noticed in Figure 8 that, in specimens which are dried along the radial direction, cracking occurred at a systematically lower average stress than in specimens dried along the axial direction. As already stated, it also occurred much earlier at a moment when the magnitude of the free shrinkage was much lower. It appears that the risk of cracking depends more on the shrinkage rate than on the actual magnitude of shrinkage. Similar observations were reported by Wei and Hansen [22] and Attiogbe et al. [20]. It is believed that high shrinkage rates induce tensile stresses early in the life of the material, too rapidly to yield enough relaxation and avoid the low early age strength to be overcome. Besides, the presumably more pronounced shrinkage gradients in the radial drying configuration result in larger self-restraint stresses (and thus larger stress concentrations), which can also explain to some extent why failure occurs earlier, under lower average stress.

Furthermore, analysis of the relationship between the cracking age and the corresponding stress rate reveals a strong correlation between the stress rate and the cracking occurrence, with higher stress rates leading to a shorter time to cracking. The result in Figure 10(b) indicates a strong power law relationship between the age of cracking and stress rate, with a coefficient of determination $\left(R^{2}\right)$ of 0.94 . The results agree well with the findings from earlier investigations $[5,13,20,23]$ that the higher the stress rate is, the shorter the time it takes to crack under restrained shrinkage. In the present study, it can be seen that higher stress rates are recorded in the radial drying layout compared to the axial drying layout. Consequently, the specimen drying along the radial direction cracked much earlier than the companion specimen dried from the axial side. This is somewhat in view of the fact that the lower stress rate allows for stresses to be relaxed over a longer period of time and to develop further strength. Overall, the stress rate approach was found to better quantify the stress of the concrete and thus provides a more fundamental way of evaluating the cracking potential of mixtures in the ring test experiment.

Also, a comparison of the results presented herein with data available in the literature [5, 13] suggests that the AASHTO ring test yields lower stress rates than those recorded with the ASTM C1581 ring test [7], which can essentially be attributed to the lower effective degree of restraint and lower $S_{e} / V$ in the test setup of the former. Thus, the stress rate limits established in past studies $[7,13]$ for a performance classification of thin-walled ASTM rings, as shown in Table 3, is not appropriate for thick AASHTO rings. Similar four performance zones, albeit slightly different stress rate limits identified for the AASHTO ring setup used in this study, are shown in Table 3. This table can be used to evaluate the relative cracking performance of materials when using the AASHTO ring test.
4.6. Effect of $w / \mathrm{cm}$ Ratio on the Age at Cracking. Test results in Figures 7, 8, and 10 clearly show that early age cracking is more likely when the $\mathrm{w} / \mathrm{cm}$ of the mixture is low. For example, shrinkage cracks occurred as early as 4 to 5 days for the mixture with the lowest $\mathrm{w} / \mathrm{cm}$ ratio exposed to drying from the radial direction. This tendency, very well documented in the literature $[4,17,24]$, is primarily due to the manifestation of autogenous shrinkage, which increases as the $\mathrm{w} / \mathrm{cm}$ decreases. Autogenous shrinkage causes the early strain and stress rates to increase, thereby increasing the potential to the shrinkage cracking in low w/cm mixtures, due to the lower tensile strength and strain capacity at an early age.

4.7. Crack Initiation and Pattern of Ring Specimen. Typical visible cracks that develop in restrained ring specimens drying from the radial and axial direction are shown in Figure $11(0.45 \mathrm{w} / \mathrm{cm}$ mixture $)$. Crack growth and width were monitored by visual inspection at time intervals of not more than 2 weeks after crack initiation. It could be assessed by visual inspection/survey that, in specimens dried along the radial direction (Figure 11(a)), cracking initiated from the outer circumference and then propagated inside the ring, while in the case of specimens dried along the axial direction (Figure 11(b)), cracking occurred at the inner circumference and propagated towards the outer edge in the rings. Using acoustic emission to monitor crack initiation and propagation, Hossain and Weiss observed the same trend [17]. As already discussed, the higher shrinkage gradients seemingly occurring in the axial drying configuration generates larger self-restraint stresses. As a result, the maximum stress occurs at the outer face of the ring specimen, where moisture loss occurs.

In this study, somewhat larger cracks were observed in specimens dried from the radial direction than in those dried from the axial direction. The average crack width for the $0.45 \mathrm{w} / \mathrm{cm}$ specimens drying along the axial direction was about $0.18 \mathrm{~mm}$, while that of specimens dried along the radial direction was approximately $0.35 \mathrm{~mm}$. Similarly, the average width of the crack of the $0.60 \mathrm{w} / \mathrm{cm}$ specimen was approximately $0.13 \mathrm{~mm}$ and $0.29 \mathrm{~mm}$ in the axial and radial direction of drying, respectively.

\section{Summary}

This research focused on the influence of drying conditions, $S_{e} / V$, and moist curing on the stress development and age at cracking in the restrained shrinkage ring experiments. The study has shown that drying condition of the concrete ring specimen has a significant impact on the shrinkage and stress rates and thus the cracking age.

It was found that the ring specimens allowed to dry along the radial direction experience higher stress rate than those allowed to dry along the axial direction. As a result, specimens drying from the radial direction were observed to be more prone to early-age cracking than to those drying from the axial direction. This can be attributed to the fact that the specimens that dry from the radial direction has a higher 


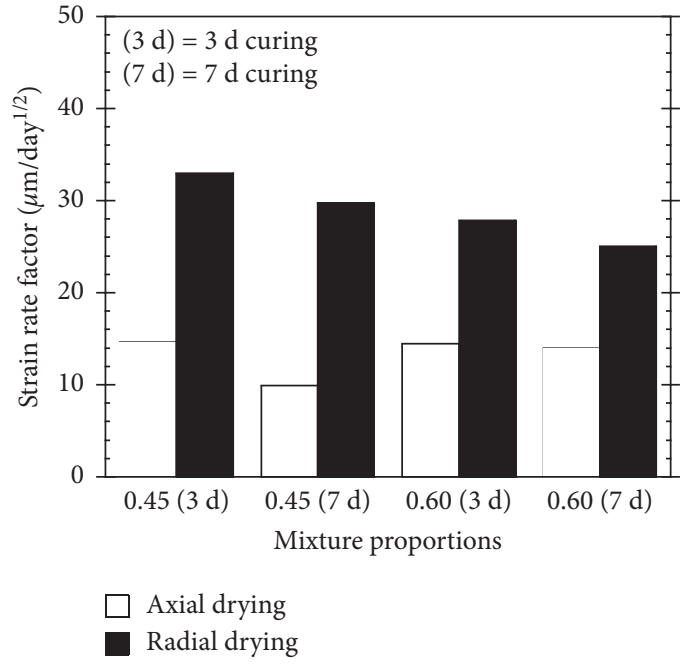

(a)

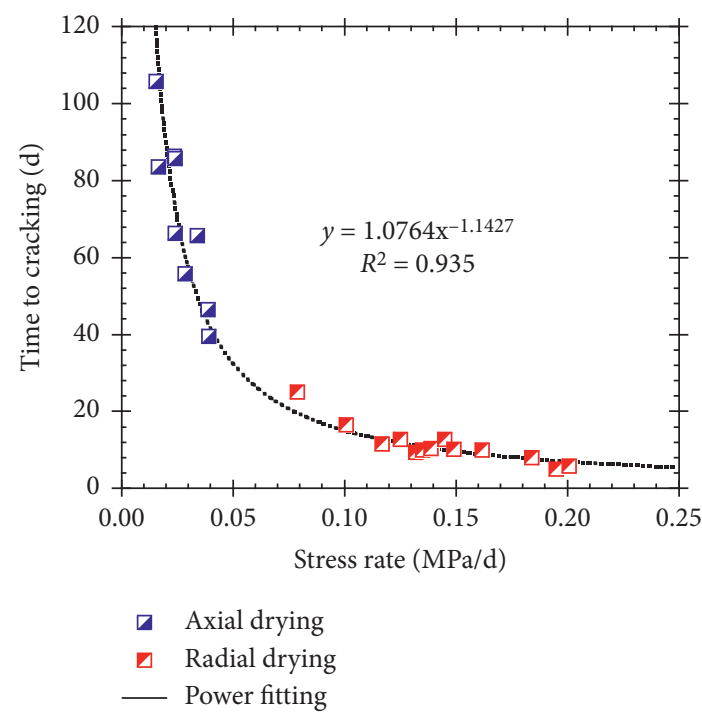

(b)

Figure 10: AASHTO T334 ring test results, strain and stress rates. (a) Strain rate factor (steel ring deformation). (b) Stress rate vs. time to cracking.

TABLE 3: Suggested cracking potential classification (based on the stress rate at cracking).

\begin{tabular}{lccc}
\hline Net time-to-cracking, $t_{\mathrm{cr}}$, (days) & $\begin{array}{c}\text { ASTM stress rate, } S, \\
(\mathrm{MPa} / \text { day) }[7]\end{array}$ & $\begin{array}{c}\text { Suggested stress rate, } S, \\
(\mathrm{MPa} / \text { day) })^{\mathrm{a}}\end{array}$ & $\begin{array}{c}\text { Potential for cracking } \\
\text { classification }\end{array}$ \\
\hline $0<t_{\mathrm{cr}} \leq 7$ & $S \geq 0.34$ & $S \geq 0.17$ & High \\
$7<t_{\mathrm{cr}} \leq 14$ & $0.17 \leq S \leq 0.34$ & $0.11 \leq S \leq 0.17$ & Moderate-high \\
$14<t_{\mathrm{cr}} \leq 28$ & $0.10 \leq S \leq 0.17$ & $0.05 \leq S \leq 0.11$ & Moderate-low \\
$t_{\mathrm{cr}}>28$ & $S<0.10$ & $S<0.05$ & Low \\
\hline
\end{tabular}

${ }^{\text {a }}$ suggested values for the AASHTO ring setup.

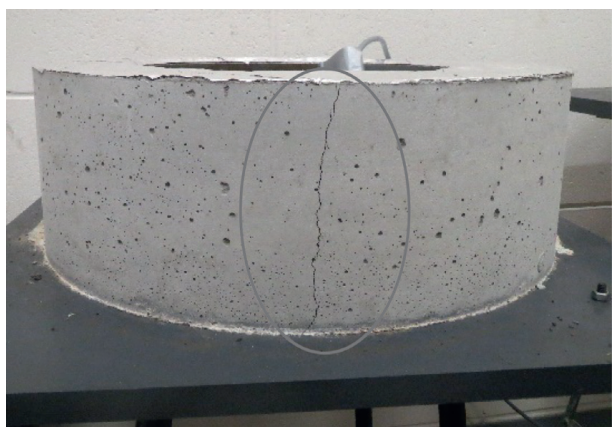

(a)

FIGURE 11: Cracking observed in restrained ring specimen $(0.45 \mathrm{w} / \mathrm{cm}$ mixture).

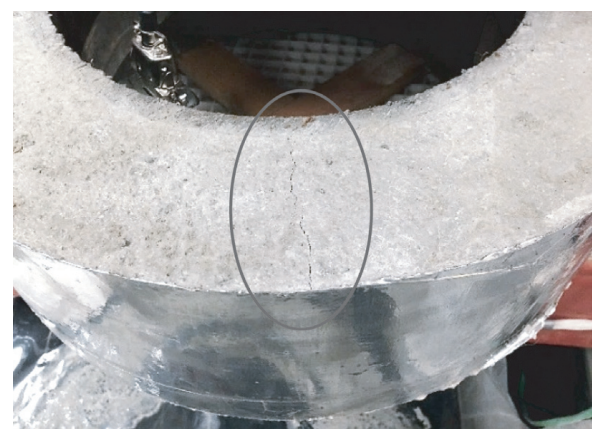

(b) exchange surface-to-volume ratio $\left(S_{e} / V\right)$ and also experience less uniform drying which increases the stress rate.

It was also found that the risk for early age cracking increases as the $\mathrm{w} / \mathrm{cm}$ of the mixture is reduced, due to the increasing contribution of autogenous shrinkage, which occurs as soon as hydration kicks in. Hence, in low w/cm materials, the self-desiccation must be considered in evaluating the risk for restrained shrinkage cracking. It has been observed that the risk for shrinkage cracking is more influenced by the shrinkage rate than the magnitude of shrinkage. To avoid or limit early cracking, it is, therefore, advisable to protect the surface of the concrete in order to reduce the shrinkage rate.

It was found that the stress rate in the ring specimen can be a better way to evaluate the potential of shrinkage cracking of mixtures due to the intrinsic material variability of concrete, which may influence considerably the age at cracking. The results further show that proper moist curing can effectively delay cracking of a concrete element under restrained shrinkage conditions. 
Furthermore, it has been found that the gradual and prolonged evolution of stresses in the case of specimens drying from axial direction allows studying the behavior of concrete mixtures over a longer period before cracking occurs. However, drying along the radial direction is recommended for faster assessment of cracking potential of shotcrete, owing to the longer test duration when drying from the axial direction.

Finally, a comparison of the free shrinkage and the corresponding strain measured in the restraining steel ring for both mixtures show that free shrinkage does not necessarily provide a reliable indication regarding the actual restrained shrinkage cracking potential of concrete. In conclusion, it should be mentioned that the study is still ongoing to quantify the influence of other important parameters on shrinkage cracking, such as the degree of restraint, the self-induced stress profile due to differential shrinkage (i.e., self-restraint), and the curing method.

\section{Data Availability}

The data of the tables are included within the article. The figure data are available on request from the corresponding author but are embedded and can be extracted easily.

\section{Disclosure}

This project is part of a long-term effort to reduce the cracking potential of concrete and shotcrete repairs and to improve their service life.

\section{Conflicts of Interest}

The authors declare that they have no conflicts of interest.

\section{Acknowledgments}

This work was conducted at CRIB (Centre de recherche sur les infrastructures en béton), Université Laval, and the authors are grateful to Mr. Jean-Daniel Lemay and Mr. Mathieu Thomassin for their outstanding technical contribution. The authors gratefully acknowledge the support received from King Shotcrete Solutions and the Natural Sciences and Engineering Research Council of Canada through their Collaborative Research and Development Program.

\section{References}

[1] J. A. Almudaiheem and W. Hansen, "Effect of specimen size and shape on drying shrinkage of concrete," ACI Materials Journal, vol. 84, no. 2, pp. 130-135, 1987.

[2] B. Bissonnette, P. Pierre, and M. Pigeon, "Influence of key parameters on drying shrinkage of cementitious materials," Cement and Concrete Research, vol. 29, no. 10, pp. 1655-1662, 1999.

[3] S. A. Altoubat and D. A. Lange, "Creep, shrinkage and cracking of restrained concrete at early age," ACI Materials Journal, vol. 98, no. 4, pp. 323-331, 2001.

[4] TRB, Control of Cracking in Concrete: State of the Art, Vol. 56, Transportation Research E-Circulars, Transportation
Research Board, No. E-C107, vol. 56, Washington, DC, USA, 2006.

[5] J. H. Ideker, T. Fu, and T. Deboodt, "Development of shrinkage limits and testing protocols for ODOT high performance concrete," vol. 87, ODOT Research Section, Oregon, OR, USA, 2013, Report no. SPR 728.

[6] AASHTO-T334-08, Standard Practice for Estimating the Crack Tendency of Concrete, Vol. 6, AASHTO Provisional Standards, Washington, DC, USA, 2012.

[7] ASTM-C1581, Standard Test Method for Determining Age at Cracking and Induced Tensile Stress Characteristics of Mortar and Concrete under Restrained Shrinkage, Vol. 7, ASTM International, West Conshohocken, PA, USA, 2009.

[8] A. B. Hossain and J. Weiss, "Assessing residual stress development and stress relaxation in restrained concrete ring specimens," Cement and Concrete Composites, vol. 26, no. 5, pp. 531-540, 2004.

[9] J.-H. Moon, B. Pease, F. Rajabipour, and J. Weiss, "Quantifying the influence of specimen geometry on the results of the restrained ring test," Journal of ASTM International, vol. 3, no. 8, pp. 1-14, 2006.

[10] F. Modjabi-Sangnier, Approche Quantitative de la notion de compatibilité des bétons de réparation autoplaçants, Université Laval, Quebec City, Canada, 2010.

[11] J. H. Moon and J. Weiss, "Estimating residual stress in the restrained ring test under circumferential drying," Cement and Concrete Composites, vol. 28, no. 5, pp. 486-496, 2006.

[12] H. R. Shah and J. Weiss, "Quantifying shrinkage cracking in fiber reinforced concrete using the ring test," Materials and Structures, vol. 39, no. 9, pp. 887-899, 2006.

[13] H. T. See, E. K. Attiogbe, and M. A. Miltenberger, "Potential for restrained shrinkage cracking of concrete and mortar," Cement, Concrete, and Aggregates, vol. 26, no. 2, pp. 1-8, 2004.

[14] S. Mindess, Developments in the Formulation and Reinforcement of Concrete, Woodhead Publishing, Cambridge, UK, 2019.

[15] S. Girard, M. Jolin, B. Bissonnette, and J.-D. Lemay, "Measuring the cracking potential of shotcrete," Concrete International, vol. 39, no. 8, pp. 44-48, 2017.

[16] A. Hossain, B. Pease, and J. Weiss, "Quantifying early-age stress development and cracking in low water-to-cement concrete: restrained-ring test with acoustic emission, transportation research record," Journal of the Transportation Research Board, vol. 1834, no. 1, pp. 24-32, 2003.

[17] A. B. Hossain and J. Weiss, "The role of specimen geometry and boundary conditions on stress development and cracking in the restrained ring test," Cement and Concrete Research, vol. 36, no. 1, pp. 189-199, 2006.

[18] AASHTO-PP-34-99, Standard Practice for Estimating the Cracking Tendency of Concrete, Vol. 4, AASHTO Provisional Standards, Washington, DC, USA, 1999.

[19] B. Menu, M. Jolin, and B. Bissonnette, "Studies on the influence of drying shrinkage test procedure, specimen geometry, and boundary conditions on free shrinkage," Advances in Materials Science and Engineering, vol. 2017, Article ID 9834159, 9 pages, 2017.

[20] E. K. Attiogbe, W. Weiss, and H. T. See, "A look at the stress rate versus time of cracking relationship observed in the restrained ring test," in International RILEM Symposium on Concrete Science and Engineering: A Tribute to Arnon Bentur, RILEM Publications SARL, Bagneux, France, 2004.

[21] B. Menu, M. Jolin, B. Bissonnette, and N. Ginouse, "Evaluation of early age shrinkage cracking tendency of concrete," in Proceedings of the CSCE Annual Conference 
on Leadership in Sustainable Infrastructure, Vancouver, Canada, June 2017.

[22] W. Dong, X. Zhou, Z. Wu, and G. Kastiukas, "Effects of specimen size on assessment of shrinkage cracking of concrete via elliptical rings: thin vs. thick," Computers \& Structures, vol. 174, pp. 66-78, 2016.

[23] Y. Wei and W. Hansen, "Early-age strain-stress relationship and cracking behavior of slag cement mixtures subject to constant uniaxial restraint," Construction and Building Materials, vol. 49, pp. 635-642, 2013.

[24] S. Tongaroonsri and S. Tangtermsirikul, "Effect of mineral admixtures and curing periods on shrinkage and cracking age under restrained condition," Construction and Building Materials, vol. 23, no. 2, pp. 1050-1056, 2009. 